Research, part of a Special Feature on Managing Surprises in Complex Systems

\title{
Urban Systems during Disasters: Factors for Resilience
}

\author{
Deborah Wallace $^{1}$ and Rodrick Wallace ${ }^{2}$
}

\begin{abstract}
Urban neighborhoods form the basic functional unit of municipalities. Socioeconomically, they consist of social networks and interlocking layers of social networks. Old, stable neighborhoods are blessed with large social networks and dense interlocking layers. Both social control and social support depend on these complex structures of tight and loose ties. Public health and public order depend on these structures. They are the basis of resilience of both the neighborhood itself and of the municipality that is composed of neighborhoods. In New York City in the 1970s and later, domain shift occurred because of the disruption of the socioeconomic structure by the massive destruction of low-rental housing. A combined epidemic of building fires and landlord abandonment of buildings leveled a huge percentage of housing in poor neighborhoods and forced mass migration between neighborhoods. Social relationships that had existed between families and individuals for decades were destroyed. Community efficacy also greatly diminished. Drug use, violent crime, tuberculosis, and low-weight births were among the many public health and public order problems that soared in incidence consequent to the unraveling of the communities. These problems spilled out into the metropolitan region of dependent suburban counties. The ability of a municipality and its dependent suburban counties to weather a disaster such as an avian flu pandemic depends on the size of social networks in its neighborhoods and on the interconnection between the social networks. Diversity such as gained by social and economic integration influences the strength of the loose ties between social networks. Poor neighborhoods with extreme resilience conferred by a dense fabric of social networks must also maintain connections with mainstream political structure or they will fail to react to both good and bad impacts and communications.
\end{abstract}

Key Words: resilience; social network; urban system

\section{INTRODUCTION}

Most people view "resilience" as the ability of an individual or group to bounce back from a blow. To ecologists, resilience is the ability of an ecosystem to absorb a blow without a meaningful change in structure or function (Holling 1973). Conversely, a brittle or fragile system with low resilience shows large changes in fundamental structure and function with impacts that would cause no response in other systems.

Ecosystem resilience can be measured in more than one way. Ives (1995) measured the tightness of the connections within the ecosystem and how greatly impacts were amplified through tight connections. In contrast, Folke et al. (2004) looked at the magnitude of the impact required to cause a regime change (i.e., a shift from a desired to less-desired state) and reviewed a variety of ecosystems that changed from a desired state providing services to an undesired state. The seminal work in the area of ecosystem resilience was that of Holling (1973), who noted that an ecosystem could absorb a chain of impacts without showing outward changes and then suddenly "flip" into an entirely different state or regime after the proverbial last straw, i.e., ecosystem as camel's back.

Biodiversity, historic trajectory, and background environment are among the factors that influence ecosystem resilience (Holling 1992, Folke et al. 2004). Gunderson and Ruttan (unpublished manuscript) reviewed concepts of ecological resilience; the roles of scale, adaptive capacity, and adaptive management; and implications for human systems impacted by disaster. Since the mid-1980s, the application of ecosystem resilience analysis to 
human systems has proven fruitful in revealing differences in their resilience, especially their responses to impacts (e.g., Wallace and Wallace 2000). Additionally, several scientists have examined the role of resilience in human outcomes without invoking ecosystem analytical methods (e. g., Masten et al. 1990).

\section{Introduction to urban systems}

Archeologists call Catalhoyuk, a site in Turkey, the first city (Hodder 2006). Several thousand people lived there in approximately $7000 \mathrm{BC}$, but without streets or apparent divisions of labor, with the possible exception of the division between men and women and between young and old. Most of what is considered inherent in cities today was missing. Catalhoyuk did not even have a necropolis; people buried their family members in the floors of their houses. However, a few thousand years later, complex cities arose in Sumeria, the Indus Valley, and China. Mohenjo-Darro in the Indus Valley had a sewage system that indicates highly developed engineering capability, symbolic markings (the meaning of which is not yet known), and a geography of occupations (craft districts; http://ww w.sjsu.edu/faculty/watkins/indus.htm). Thus, from amorphous conglomerations of houses, cities evolved rapidly into sites of complex interacting systems characterized by sophisticated infrastructures and cultures.

Approximately one-half of the world's population now lives in urban areas (United Nations 2008). In the United States, over three-quarters of the population has lived in urban areas (i.e., cities and their dependent suburbs) since approximately 1970 (United States Census Bureau 1974). Some cities such as Boston, New York, and Baltimore are older than the country, whereas others such as San Jose and Phoenix only recently erupted in growth to become some of the largest 25 cities in the country. Since the 1980 census (United States Census Bureau 1984), demographers have analyzed patterns of boom and bust among the major cities, boom in the South and Southwest, and bust in the old industrial areas of the Northeast and Midwest. These patterns of boom and bust are not "natural" aging processes as in a natural ecosystem, but rather products of policy at every level of political organization. An example of such a policy is the Southern Strategy of the Nixon administration, which channeled resources toward Sunbelt states and away from the Northeast and Midwest (Schulman 2001).

The importance of deliberate policy implementation in determining the resilience of cities cannot be understated (Wallace and Wallace 1998). Policy implementation may even overwhelm the dictates of ecosystems with respect to urban population and its needs. The irrational rise of the Sunbelt cities has led to water wars, first in the semi-arid Southwest, which has always been water-poor, and now in the Southeast, which has been in the grip of a drought of many years. Even the normally wet Northwest has been the site of gun-toting farmers claiming water from systems that had been partitioned between natural populations, urban human populations, and agricultural irrigation systems. Water resources are one example of ecosystem services on which cities depend and which depend on ecosystem resilience for continuity of service. A two-way street has developed between urban settlement and ecosystem: the resilience and maintenance of a desirable configuration of the ecosystem is a pillar of desirable urban configuration and the resilience that can maintain it; desirable urban configuration and function minimizes impacts to the ecosystem and keeps it resilient. Other ecosystem services on which cities depend include natural areas for recreation and local climate moderation, the presence of predators to control prey populations ("prey" can range from deer to mosquitoes), and the various soil processes that support the growth of beneficial plants. The failure of urban resilience often translates into a failure to manage ecosystems for optimal resilience. For example, suburban sprawl as an outgrowth of configuration flip in core cities is described in Introduction: Metropolitan regional systems. Gunderson and Ruttan (unpublished manuscript) describe the requirements for managing ecosystems for optimal resilience.

Core cities of the United States present a spectrum of potential resilience, and their suburbs depend on them, even if the suburbs themselves feature high incomes, low crime rates, and all desirable amenities. We next describe this dependence in more detail. 


\section{Urban functions that allow high population density}

The population densities that are reached in modern cities inherently pose a variety of risks: fire, building collapse, disease, thirst, hunger, violence, and simple filth. A complex web of governmental and private systems arose to prevent and control fires, ensure structurally sound housing, prevent and control contagious diseases, supply safe water, get food to the populace, enforce standards against violence, impose basic sanitation both with respect to human waste and with respect to garbage, supply electrical power, and provide transportation modes that support all of the above. The discipline of urban planning emphasizes these primary functions of cities and their dependent metropolitan regions.

The dense urban neighborhood, defined as an area that one can walk across in one-quarter to one-half hour (approximately $2.5 \mathrm{~km}$ ), may contain as few as 3000 or as many as 250,000 people. It constitutes the smallest unit of the mesoscale, as defined by Holling (1992), and is the primary unit of contagious urban processes, whether they be infectious disease in epidemics (e.g., tuberculosis; Wallace 1994), fire (Wallace and Wallace 1983), or contagious behavioral patterns such as the abuse of illegal drugs (Hunt and Chambers 1976).

Neighborhoods are both physical and socioeconomic entities. Granovetter (1973) examined geographically based social networks (i.e., strong ties) and the interactions between people of differing social networks (i.e., weak ties). His examination was an early analysis of one basis for socioeconomic resilience: a dense mass of social networks that interact. Socioeconomic resilience means that the social and economic structure of the neighborhood absorbs impacts without major change. If an economic recession occurs, the dense fabric of weak and strong ties facilitates, for example, the sharing of resources to tide over affected families and individuals. Stack (1974) and Susser (1982) each performed anthropological studies of how neighborhoods function to keep poor women and their families housed, fed, and clothed. These studies illustrated Grannovettor's (1973) concept. Although poor families and individuals depend more heavily for survival on strong and weak ties, all families and individuals need them at some time or other. Masten and Obradovic (2007) described resilience in the context of human development, namely the sequelae of impacts on children and their life courses. They placed these sequelae in the context of family and of neighborhood institutions such as the school and the community social structure in a cross-scale analysis.

Urban areas are as dependent on the healthy functioning of neighborhoods as on municipal services and private enterprise for the delivery of necessities. Well-functioning communities provide services, just as well-functioning ecosystems provide services. Without social control, for example, even the highest level of policing would not be able to keep violent crime rates low. Even very high levels of public health activity would be unable to keep diseases in check without the support of the social fabric of neighborhoods in favor of preventive behaviors. Most pertinently, in this era of disaster and terrorism scholarship, social networks are mobilized in disasters to pick up the pieces and save families and the community (Solomon 1986).

However, in the 1970s and 1980s, social control and support ebbed steeply in inner-city neighborhoods. Tuberculosis, violence, sexually transmitted diseases, and drug abuse were four of many conditions that soared in incidence and prevalence, peaking in the late 1980s and early 1990s (Wallace and Wallace 1998). Social control and support depend on the social stability of neighborhoods, which in turn depends on municipal services and certain private services that ensure the physical stability of housing.

\section{The role of neighborhoods in urban resilience}

The neighborhood forms a critical level of organization between the individual or family level and the municipality and metropolitan region. Masten and Obradovic (2007) described the linkage between the individual and family to the larger social environment of neighborhood entities such as the school and the neighborhood social network and how that linkage influences individual resilience and family function.

Although literature from the Reform Era explored the role of housing in the socioeconomic function of neighborhoods (e.g., Griscom 1844), modern appreciation for this role arrived with so-called urban renewal. Schwartz (1993) conducted a detailed analysis of the outfall of urban renewal in New York City, and Fullilove (2004) examined the 
impact of urban renewal on all of the traditional African-American neighborhoods in the United States, with a detailed examination of Roanoke, Virginia, and Pittsburgh, Pennsylvania. The dislocations imposed by urban renewal broke social networks and the ties between social networks. Schwartz described the loss of social control and support and the resulting rise of drug abuse, alcoholism, promiscuity, and poverty, which led many groups, including major religions, to oppose urban renewal and make it politically unacceptable.

Even the public health community, which had looked on slums as "hives of sickness" from the getgo (Rosner 1995), began to question whether the social cost of forced dislocation attendant on the demolition of slums and building of high-rise public housing outweighed the benefits (Hinkle and Loring 1977). Such luminaries as Lorin Hinkle and Leonard Duhl (the founder of the Healthy Cities movement), who worked in the Centers for Disease Control during the Carter Administration, could not find health or mental health benefits from the new public housing, but did find benefits from other elements of the Model Cities Program, which engaged and empowered neighborhood groups (Duhl 1990).

Thus, municipal services and real estate practices that preserve housing are critical for the socioeconomic resilience of neighborhoods. We have studied the cascade of impacts resulting from the closing of fire companies in the poor neighborhoods of New York City in the 1970s. Fire in New York, and probably in other densely populated cities, can become a contagious process in the absence of adequate fire control services and in the presence of dense stands of overcrowded, undermaintained dwellings (Wallace 1978).

Indeed, the fire epidemic of the 1970s in New York and in many other older cities such as St. Louis, Missouri; Washington, D.C.; and Philadelphia, Pennsylvania, interacted with an epidemic of landlord abandonment of buildings to result in massive housing destruction (Wallace 1989). We illustrate the percentage of New York City housing that was destroyed between 1970 and 1980 (Fig. 1), the time trend of fire damage across New York City (Fig. 2), and the massive migrations made within New York City between 1970 and 1980 from neighborhoods with a high density of destroyed housing units to other neighborhoods (Fig. 3). Because of the changes in patterns of housing overcrowding and the social and physical disruption from mass migrations, the middle class left the city en masse between 1970 and 1980; 1.3 million white people left New York City in that decade (United States Census Bureau 1984). Middle-class AfricanAmericans also left; the congregation of the famous Abyssinian Baptist Church in Harlem plummeted from over 20,000 in 1972 to approximately 6000 in 1984 (Reverend Carl Butz personal communication).

New York City actually experienced an increase in racial segregation between 1970 and 1980 (Massey and Denton 1993). In ecological parlance, the diversity of individual neighborhoods generally declined. For example, the Italian presence in East Harlem almost disappeared, and East Harlem truly became Spanish Harlem. Central Harlem had health areas (aggregations of approximately 10 census tracts) that had approximately 98\% AfricanAmerican population by 1980 . This level of segregation means that there are very few opportunities for weak ties between social networks of differing characteristics, a steep loss of resources for resilience.

The effects of segregation were exacerbated by the instability of the population. The decades of building social, economic, and political structure were ruined in approximately half a decade (Wallace 1991a). Not only were the opportunities for weak ties severely cut, but even the networks of strong ties unraveled into small fragments (Wallace 1991b). Sampson et al. (1997) found that community efficacy requires residential stability. A geographical place where residents come and go cannot develop community efficacy.

A neighborhood with a high prevalence of small, tight, isolated social networks is brittle. Not only are the resources within each little group thin in the event of need, but the isolation renders each group prone to behaviors that are not welcome in the larger society. We compared the resilience structure of the South Bronx with that of Upper Manhattan. In the South Bronx, paradoxically, the housing destruction was so intense and geographically widespread that it selected for large social networks and mixed African-American and Latino populations. This mixing resulted in increased integration. In contrast, in Upper Manhattan, the housing destruction left small, tight social networks and greatly increased segregation (Wallace and Wallace 2000). Using the rate of low-weight births and the incidence of homicide as outcomes, we adapted the Ives measure of ecosystem resilience (Ives 1995) and found that 
Fig. 1. Percent loss of housing units in (A) New York City and (B) the Bronx between 1970 and 1980. The geographic units are the designated health areas that encompass 10 census tracts; at the time of designation in the 1960s, they were socioeconomically homogeneous, with average populations of 20,000. The areas that lost $>20 \%$ of housing units are all in zones with high levels of poverty: South Bronx, Harlem, the Lower East Side, and the poverty belt of Brooklyn from Bedford-Stuyvesant through Brownsville/East New York.
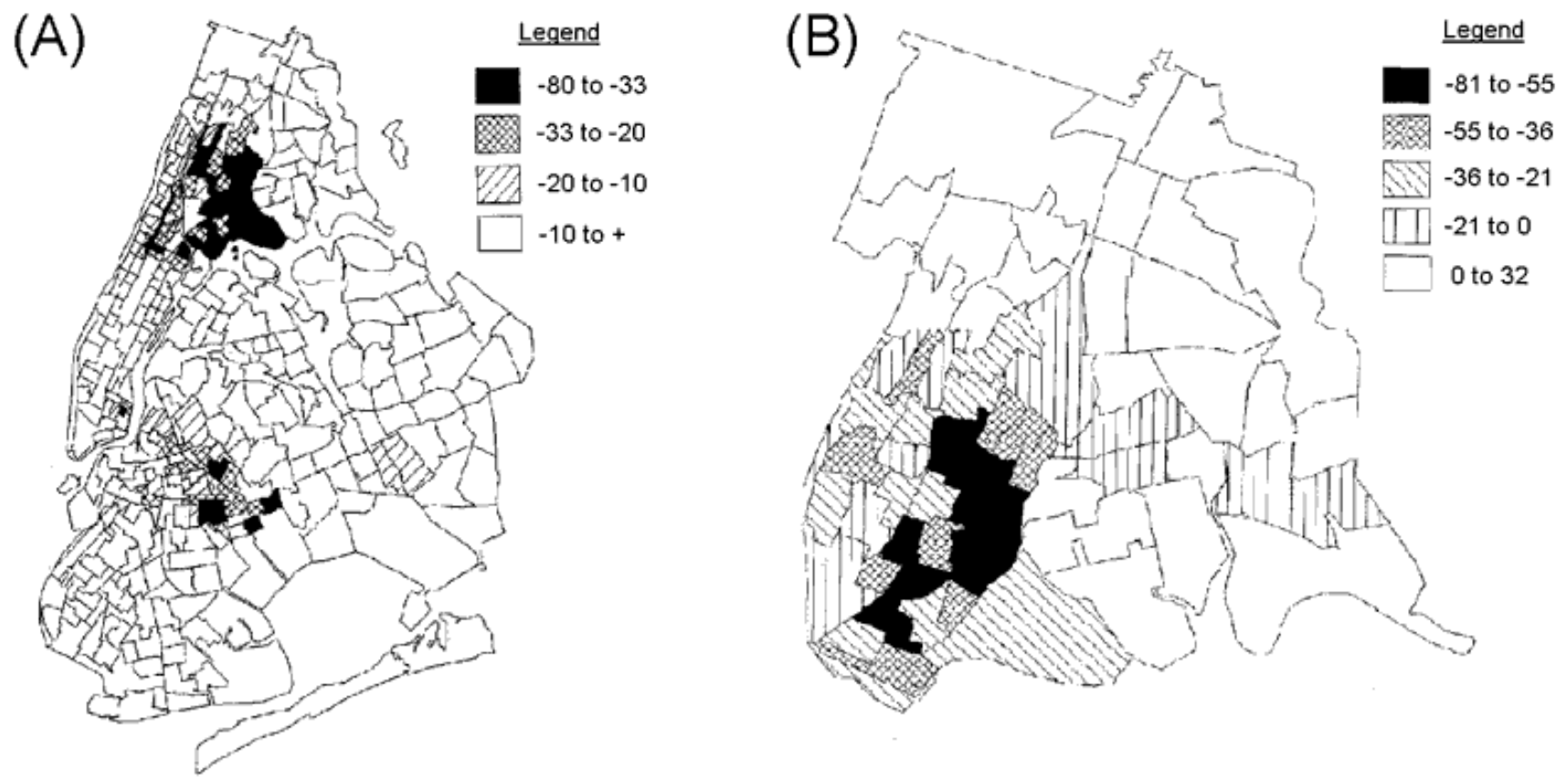

the amplification factor, an indication of how greatly an impact would be amplified along tight ties, was approximately five times greater in Upper Manhattan than in the South Bronx.

The rather high resilience of the South Bronx is both a blessing and a curse. Although impacts may roll off it like water off a duck, bringing beneficial changes may also prove difficult. Any change may prove hard to initiate. This resilience may confer the ability to absorb both good and bad impacts with little or no change.

The mere presence of contagious phenomena implies the resilient behavior of a system. Epidemic contagion occurs after a threshold is reached. For example, in infectious disease epidemiology, an epidemic threshold is defined by the density of infected and infectious individuals and susceptible individuals (Bailey 1975). In the parlance of ecosystem resilience, the system will absorb impacts until it reaches a threshold and crosses into the domain of epidemic contagion. We have studied building-fire epidemics (Wallace and Wallace 1998), but Dear (1976) and Odland and Balzer (1979) studied building-abandonment epidemics in Philadelphia, Pennsylvania, and Indianapolis, Indiana, respectively. During the 1970s, many large cities in the United States suffered from massive losses of housing, especially low-income housing, because of these epidemics.

Approximately $15 \mathrm{yr}$ after the end of the fire epidemic in New York City, the cascade of effects began to reverse. Violent crime, tuberculosis, and acquired immune deficiency syndrome (AIDS) began to decline, even before the availability of highly active antiretrovirus therapy for AIDS and directly observed therapy for tuberculosis. We conclude that $15 \mathrm{yr}$ was needed to allow the 
Fig. 2. Annual index of fire damage in New York City for 1959 to 1986 . The index of fire damage is based on the hours of firefighting time, number of building fires, and number of serious fires, i.e., those requiring more than a first alarm assignment of engines and ladders. The plot over time shows a classic epidemic curve.

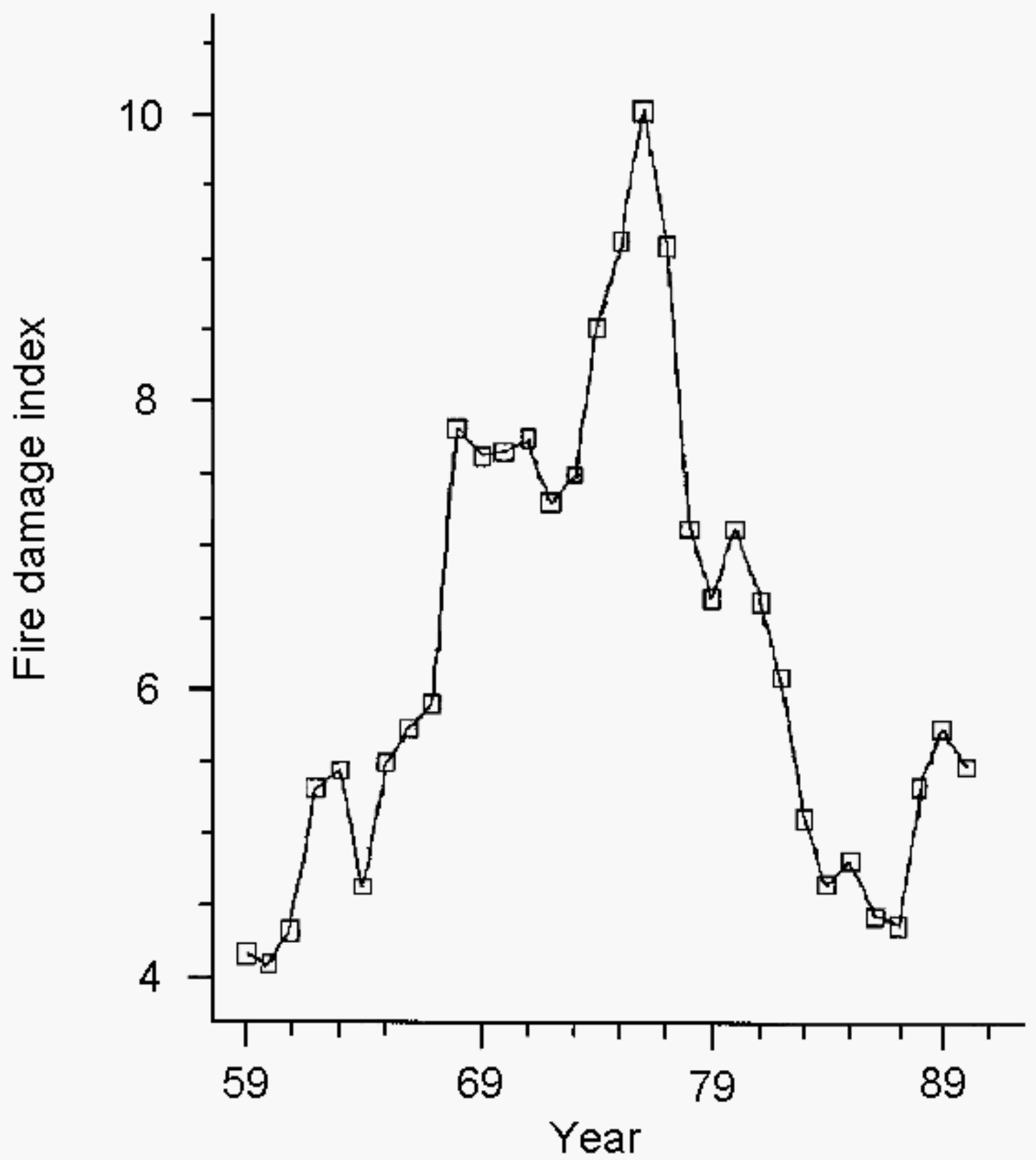


Fig. 3. Change in the black population in New York City for 1970 to 1980 . Changes of $\geq 2500$ people refer to census tracts. The hatched and black areas are composed of many census tracts. This map shows that hundreds of thousands of people migrated within this single decade. The mini-census of 1975 indicated that most of the migration occurred between 1975 and 1980, with the exception of the South Bronx.

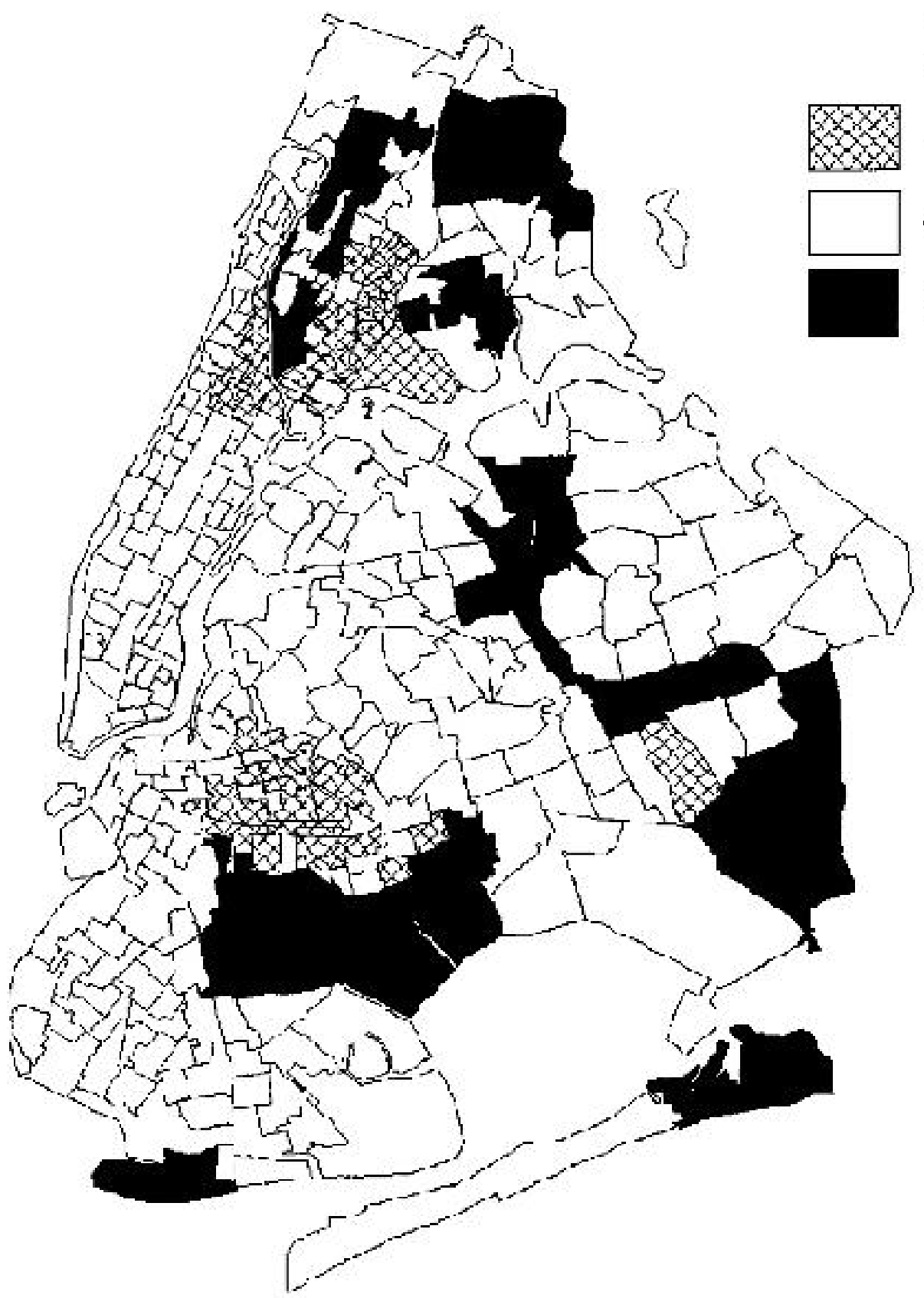

Legend

-2500 or more

-2500 to 2500 2500 or more 
regrowth of social networks and ties between social networks. The poor neighborhoods determined the municipal processes both during the deterioration of the late 1970s to early 1990s and during the post-1993 rehabilitation because of the cross-scale phenomenon of contagion. Thus, two scales depended on the public and private policies, the implementation of which destroyed a large proportion of the housing of the poor: neighborhoods and entire cities.

The $15 \mathrm{yr}$ of repair led to a sudden domain change, a mark of a resilient system. The murder rate, new incidences of tuberculosis, and new incidences of human immunodeficiency virus (HIV) infections suddenly declined rapidly beginning in 1993. This domain change was a return toward the previous condition of stable neighborhoods. We speculate that large social networks and dense ties between them form the deepest "energy well" of human systems, the state to which the system returns from nearly all perturbations. This return arises from thousands of years of global human cultural evolution. Most of the world's religions have laws to stabilize human relations with particular structures and functions that foster continuity. This stability, in turn, fosters low levels of violence and disease. In this way, human systems, which are products of both cultural and biological evolution, differ from ecosystems, which do not readily return to the former domain after an impact-driven domain shift.

Like those of natural ecosystems, however, the resilient properties of neighborhoods and cities depend on historical trajectories, including past impacts. The timeframes of post-disaster recovery are dictated by the nature of the disaster, its intensity and extent, and the state of the receiving system. Wallace et al. (2007) found that the major difference between "good" and "bad" neighborhoods in New York City with respect to the impact of building fires on AIDS death rates was the protection of "good" neighborhoods from fire occurrence. The Ives amplification factor for neighborhood-level determinants of AIDS death rates was similar for both types of neighborhood.

Resilience timeframes for American neighborhoods may have been selected by the regularity of changes in urban policies: approximately every $15-20 \mathrm{yr}$. In the $1950 \mathrm{~s}$, urban renewal clearcut "bad" neighborhoods in most major cities. In the 1970s, Benign Neglect and Planned Shrinkage leveled "bad" neighborhoods through the denial of housing preservation services such as fire control. In the 1990s, Hope VI implemented the demolition of public housing built during the 1950s and 1960s as part of urban renewal. In addition to the reconstruction of intergeneration weak and strong ties within neighborhoods, selection would have driven neighborhoods to re-empower themselves within 15 yr or be unprotected prey for the next wave of destructive policy aimed at poor neighborhoods of color. Examples of cities that did not re-organize and were largely destroyed by urban renewal followed by Benign Neglect or Planned Shrinkage include Detroit, Michigan; Newark and Camden, New Jersey; St. Louis, Missouri; and Baltimore, Maryland. Although human culture provides impetus toward social ties and thus toward the restoration of social structure in impacted neighborhoods, the timescale of this restoration, which must link both within age groups and between age groups, may be an outcome of selection pressure.

Various cities have pursued different policies both recently and historically. San Francisco, California, did not destroy its old residential buildings and showed markedly different dynamics of disease and violence from New York City and other cities that engaged in urban renewal and planned shrinkage. Other cities that did not participate in contagious urban decay include Portland, Oregon; Minneapolis, Minnesota; and Seattle, Washington. Although San Francisco, and presumably the other nondecaying cities, had hot spots of AIDS, tuberculosis, and violence, it did not show the kind of epidemic spread through the municipality and through the metropolitan region that characterized that in New York City, Philadelphia, Washington, D.C., and other cities suffering from contagious urban decay. The cities that did not adopt policies that fostered the destruction of housing merely continued their developmental trajectories, whereas those that encouraged housing destruction experienced regime change. St. Louis and Detroit, indeed, accelerated their downward spiral and now compete for the crown of most violent city in the United States. Public and private policies determine the life stages of cities and their life-history trajectories. 


\section{Metropolitan regional systems}

The designation of metropolitan regions by the United States Census Bureau depends on the commuting pattern, i.e., the percentage of workers in suburban counties that travel into the core city each workday. Dependent counties have a minimum of approximately 5\% of resident workers who journey into the city. Each metropolitan region has its journey-to-work matrix, which shows the number of workers who live in each county and in the core city and the number of those who work in each county and in the core city. Because of core city dominance, the socioeconomic dynamics, public health, and public order in the dependent counties may be deeply influenced by those of the core city. A study by Viboud et al. (2006) of the spread of ordinary flu showed that commuting patterns determined patterns of flu spread, with typical hierarchical spread followed by simple diffusion.

We have analyzed the role of links, as indicated by the commuting matrix, within metropolitan regions in the spread of AIDS, tuberculosis, violent crime, and low-weight births during the 1980s to early 1990s (Wallace et al. 1997). In brief, the different metropolitan regions show somewhat different degrees of "regionalization" (i.e., tight linkage). These differences depend on their histories, especially on the fate of the core city: was it or was it not subject to massive housing destruction? The degree to which a county is influenced by the core city is also determined by its local vulnerability, as indicated by its poverty rate. However, we found that in tightly linked systems such as the New York City or the Washington, D.C., metropolitan region, even wealthy counties within the region are influenced by the core city during epidemics (Fig. 4). Thus, particular ways and degrees of stressing the core city tighten the links with the counties and produce a more brittle, less resilient metropolitan region.

Very recent work shows that a period of rehabilitation of the core city may lead to the weakening of ties between the counties and the core city and a return of resilience (Wallace and McCarthy 2007). This period is the neighborhood resurrection time of 15-20 yr. Thus, the poor neighborhoods of core cities influence the processes of whole municipalities and their dependent counties in the metropolitan region. Epidemics spread rapidly through these geographic areas, first by hierarchical spread and then by spatial diffusion from the hierarchical epicenters. However, the recovery from epidemics and their outfalls may be much slower than the epidemics themselves.

\section{URBAN RESILIENCE AND PANDEMIC AVIAN FLU}

Various scenarios for the avian flu pandemic posit infection and case:mortality rates similar to those of the 1918-1919 Spanish flu pandemic (Fabian 2006). Crosby (2003) provides detailed information on the 1918-1919 flu and its dynamics. In a very short time, a high percent of a city's population (approximately one-third) will have the disease. How a city and its dependent counties weather a pandemic will depend on the history of the neighborhoods, the city as a whole, and the metropolitan region. If the social networks in neighborhoods are large and robust, with many ties between them and with ties to the political structure, information will flow rapidly and concerted action will be taken to minimize the number of infections and the impact of the ones that do occur. Children and the dependent elderly will be cared for if the responsible adults become ill. The ties to the political structure will prevent the "South Bronx paradox," the extreme resilience that minimizes both bad and good impacts; the neighborhood will be open to good impacts and absorb the bad ones.

If the social networks are small, tight, and isolated, the flow of information will be slow, if it occurs at all. Information may not be accepted because it comes from the authorities deemed responsible for the bad condition of the neighborhood. Longstaff and Yang (2008) describe the role of trust in communication during a disaster such as pandemic flu.

The USA has a vast communications industry: mass media, telecommunications, and governmental resources. In a flu pandemic, these vast resources would be mustered at all levels of organization to minimize losses by offering information and directives. When residents feel part of society, they respond with alacrity to social needs. The incredible vaccination program that prevented a small pox epidemic in New York City in 1947 (Rosner 1995) depended on the response of residents to the authorities' pleas to get vaccinated: millions of people were vaccinated in less than 2 wk! Community leaders, the clergy, and the schools 
Fig. 4. Log new case incidence of AIDS, tuberculosis, and violent crime in New York City plotted against the composite index for commuting and poverty. Mu/Area is the county index of commuting density (see Wallace et al. 1997) and Perpov is the percentage of a county's population that is in poverty. Each data point represents one of the 24 counties of the New York City Metropolitan Region, including the five boroughs. These regressions are parallel, as indicated by analysis of covariance.

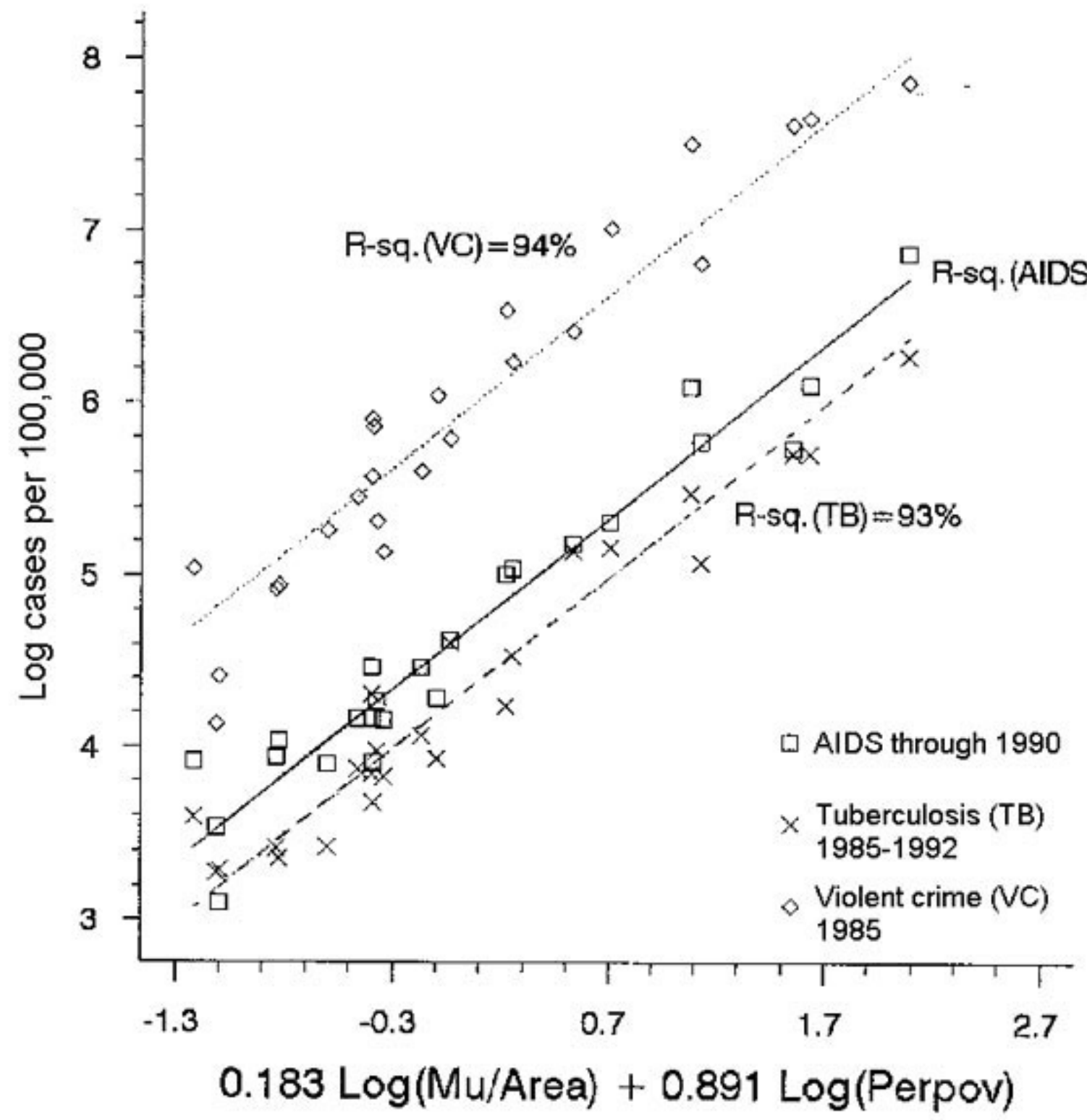


were part of the mobilization effort. Residents received the message to get vaccinated from the radio, from distributed governmental pamphlets, and from their neighbors, civil servants, and spiritual leaders. They also passed the word to others and organized vaccination trips to the public health dispenseries. This involvement of residents and their local leaders stopped the outbreak in its tracks. However, 1947 was only 2 yr after the end of World War II, when everyone became accustomed to working together and pitching in to help.

In contrast, the failure of the 1976 swine flu vaccination program illustrates the role of trust that Longstaff and Yang (2008) describe. The need for such a program was not demonstrated to the public. Additionally, American society had become deeply fragmented by resegregation and the targeting of poor urban neighborhoods for destruction. In short, the role of communication in an outbreak with potential to become a pandemic depends on the state of urban social structure and the caring authenticity of the messages generated by the authorities.

In fragmented neighborhoods with small, tight social networks, communication will flow slowly between social networks. Some social networks will not believe the information because the authorities are not trusted. Indeed, it may be that the pandemic will gather momentum fastest in these neighborhoods because of the failure to engage the residents. Additionally, after the pandemic takes hold, the resources in these fragmented neighborhoods will not be pooled to care for the children and dependent elderly in the case of illness among the normal caregivers.

Although the 1918 pandemic featured "democratic" infection (spread through all socioeconomic classes), current fragmentation and segregation may lead to inequalities in infection rates. If only the upper and middle classes act on communications about ways to minimize the probability of infection, they will clearly suffer lower infection rates than will working-class and poor neighborhoods. This is one mechanism that results in poorer health in poor neighborhoods, especially poor neighborhoods of color. Another possible mechanism is the "South Bronx paradox" whereby extreme resilience precludes change, even if the change is needed. Flu, however, is unlike tuberculosis in that it attacks everyone that is not immunized against it. Indeed, the very healthy are more likely to die of fulminating lung inflammation because of the strong reaction of a healthy immune system to avian flu. Tuberculosis, on the other hand, is usually fended off by a strong immune system so that exposure does not progress to infection and infection does not progress to active disease.

Other mechanisms that could lead to inequalities in avian flu disease incidence and mortality rates among socioeconomic groups include differing population densities and housing overcrowding, which both influence rates of transmission, and differing access to medical care, which influences mortality rates. If the inequality in infection is extreme enough, poor neighborhoods would become pandemic epicenters from which the disease would spread more rapidly than if infection rates were roughly equal and diffuse throughout the urban population.

The state of the municipal and private services will also influence the size and impact of the local pandemic. If the workforces for these services have been cut to the bone, illness-related absences will render these services inadequate. A municipality cannot simply recruit firefighters, police officers, water supply engineers, and other necessary workers right off the street. Likewise, many private service roles, e.g., plumbers, electricians, phone technicians, cannot be filled by just anyone. Most large cities require training, experience, and demonstrated competence of their vital workers because these jobs are difficult, tricky, and utterly fundamental to the lives and health of the populace. Many private service roles require periods of apprenticeship and tests of competence.

Inadequate services can lead to contagious urban processes such as housing destruction, violent crime, and drug abuse. These processes, in turn, feed into the whittling of urban resilience into brittle fragility, as we have described above. When the contagion grows intense enough, it spills over into the rest of the metropolitan region, resulting in a brittle region. The loss of resilience and diminution of the ability to minimize the pandemic and its effects would not be confined to the core city and its neighborhoods.

Once contagious processes are triggered, they are difficult to stop and render conditions in the affected areas unacceptable to many residents. The secondary contagious processes may last much longer than the primary one (the pandemic). If this occurs, the residents with resources will leave for 
less intensely affected areas, as they did in the 1970s. The emigration will again reduce the opportunities for the ties between social networks that are brought about by integration and diversity.

\section{RECOMMENDATIONS FOR INCREASING URBAN RESILIENCE}

We provide several recommendations to prevent domain shift and to direct it toward less harmful configurations if it does occur. If contagious processes can be prevented or nipped in the bud, urban systems will function with no or only minor shifts in structure and function. The key is to prevent contagious urban processes.

1. Apply techniques to multiply weak ties; e.g., form alliances of houses of worship of all faiths for neighborhood projects;

2. Encourage the ethnic and economic integration of neighborhoods; e.g., deliberately construct new housing and refurbish old housing for an economic mix of families and individuals;

3. Provide adequate municipal and private services to prevent contagious urban processes; e.g., allocate housing preservation services that fit the heaviest demand of each neighborhood, as defined by ecological analyses;

4. Plan for the pandemic by providing for adequate municipal and private services, even in the event of the illness of large proportions of the workforce; e.g., plan the supply of equipment and workforce in a manner similar to that prescribed by the Kerner Commission for a massive riot, including stocking up on extra fire hose, fire trucks, ambulances, and police vehicles, as well as developing a method to call in offduty personnel and a special reserve of personnel from other areas;

5. Ensure adequate services, especially in poor neighborhoods, which are the keystone populations of metropolitan regions; e.g., establish standards for housing unit loss per unit population per year, monitor neighborhoods for housing loss and intervene promptly in neighborhoods when the loss exceeds the standard after ascertaining the causes of the loss and the particular services that need changing.

Responses to this article can be read online at:

http://www.ecologyandsociety.org/voll3/iss1/art18/responses/

\section{Acknowledgments:}

We thank one anonymous reviewer for wise and useful comments.

\section{LITERATURE CITED}

Bailey, N. T. J. 1975. The mathematical theory of infectious diseases and its applications. Second edition. Griffin, London, UK.

Crosby, A. W. 2003. America's forgotten pandemic: the influenza of 1918. Second edition. Cambridge University Press, Cambridge, UK.

Dear, M. J. 1976. Abandoned housing. Pages 59-99 in J. S. Adams, editor. Urban policymaking and metropolitan dynamics: a comparative geographical analysis. Ballinger, Cambridge, Massachusetts, USA.

Duhl, L. J. 1990. Comprehensive city interventions. Bulletin of the New York Academy of Medicine 66(5):547-557. Available online at: http:/ /www.pubmedcentral.nih.gov/articlerender.fcgi? artid=1809775.

Fabian, N. 2006. H5N1: a special report-What is the threat and why should the environmental health profession be concerned? Journal of Environmental Health 68(6):46-63.

Folke, C., S. Carpenter, B. Walker, M. Scheffer, T. Elmqvist, L. Gunderson, and C. S. Holling. 2004. Regime shifts, resilience, and biodiversity in ecosystem management. Annual Review of Ecology, Evolution, and Systematics 35:557-581.

Fullilove, M. T. 2004. Root shock: How tearing up 
city neighborhoods hurts America, and what we can do about it. One World/Ballantine Books, New York, New York, USA.

Granovetter, M.S. 1973. The strength of weak ties. American Journal of Sociology 78(6):1360-1380.

Griscom, J. 1970. The sanitary condition of the laboring population of New York. Arno Press, New York, New York, USA. Reprint of 1844 original published by Harper, New York, New York, USA.

Hinkle, Jr., L. E., and W. C. Loring, editors. 1977. The effect of the man-made environment on health and behavior: a report of the inter-university board of collaborators. DHEW Publication Number (CDC) 77-8318. Centers for Disease Control, Atlanta, Georgia, USA.

Hodder, I. 2006. This old house: At Çatalhöyük, a Neolithic site in Turkey, families packed their mudbrick houses close together and traipsed over roofs to climb into their rooms from above. Natural History Magazine 115:42-47.

Holling, C. S. 1973. Resilience and stability of ecological systems. Annual Review of Ecology and Systematics 4:1-23.

Holling, C. S. 1992. Cross-scale morphology, geometry, and dynamics of ecosystems. Ecological Monographs 62:(4)447-502.

Hunt, L. G., and C. D. Chambers. 1976. The heroin epidemics: a study of heroin use in the United States, 1965-1975. Spectrum Publications, New York, New York, USA.

Ives, A. R. 1995. Measuring resilience in stochastic systems. Ecological Monographs 65(2):217-233.

Longstaff, P. H., and S.-U. Yang. 2008. Communication management and trust: their role in building resilience to "surprises" such as natural disasters, pandemic flu, and terrorism. Ecology and Society 13(1): 3. [online] URL: http://www.ecology andsociety.org/vol13/iss1/art3/.

Massey, D. S., and N. A. Denton. 1993. American apartheid: segregation and the making of the underclass. Harvard University Press, Cambridge, Massachusetts, USA.

Masten, A. S., K. M. Best, and N. Garmezy. 1990.
Resilience and development: contributions from the study of children who overcome adversity. Development and Psychopathology 2:425-444.

Masten, A. S., and J. Obradovic. 2007. Disaster preparation and recovery: lessons from research on resilience in human development. Ecology and Society 13(1): 9. [online] URL: http://www.ecology andsociety.org/vol13/iss1/art9/.

Odland, J., and B. Balzer. 1979. Localized externalities, contagious processes and the deterioration of urban housing: an empirical analysis. Socio-Economic Planning Sciences 13 (2):87-93.

Rosner, D., editor. 1995. Hives of sickness: public health and epidemics in New York City. Rutgers University Press, New Brunswick, New Jersey, USA.

Sampson, R. J., S. W. Raudenbush, and F. Earls. 1997. Neighborhoods and violent crime: a multilevel study of collective efficacy. Science 277:918-924.

Schulman, B. J. 2001. The seventies: the great shift in American culture, society, and politics. Free Press, New York, New York, USA.

Schwartz, J. 1993. The New York approach: Robert Moses, urban liberals, and redevelopment of the inner city. Ohio State University Press, Columbus, Ohio, USA.

Solomon, S. D. 1986. Mobilizing social support networks in times of disaster. Pages 232-263 in C. R. Figley, editor. Trauma and its wake, volume II. Traumatic stress disorders: theory, research, and treatment. Brunner/Mazel, New York, New York, USA.

Stack, C. B. 1974. Allour kin: strategies for survival in a black community. Harper and Row, New York, New York, USA.

Susser, I. 1982. Norman Street, poverty and politics in an urban neighborhood. Oxford University Press, New York, New York, USA.

United Nations. 2008. World urbanization prospects: the 2007 revision population database. United Nations Department of Economic and Social Affairs, Population Division, New York, New York, 
USA. Available online at: http://esa.un.org/unup.

United States Census Bureau. 1974. 1970 city and county data book. Bureau of the Census, Washington, D.C., USA.

United States Census Bureau. 1984. 1980 city and county data book. Bureau of the Census, Washington, D.C., USA.

Viboud, C., O. N., Bjørnstad, D. L. Smith, L. Simonsen, M. A. Miller, and B. T. Grenfell. 2006. Synchrony, waves, and spatial hierarchies in the spread of influenza. Science 312:447-451.

Wallace, D. 1994. The resurgence of tuberculosis in New York City: a mixed hierarchical and spatially diffused epidemic. American Journal of Public Health 84(6): 1000-1002.

Wallace, D., and R. Wallace. 1998. A plague on your houses: how New York was burned down and public health crumbled. Verso, London, UK.

Wallace, D., and R. Wallace. 2000. Life and death in Upper Manhattan and the Bronx: toward an evolutionary perspective on catastrophic social change. Environment and Planning A 32 (7):1245-1266.

Wallace, R. 1978. Contagion and incubation in New York City structural fires 1964-1976. Human Ecology 6(4):423-433.

Wallace, R. 1989. "Homelessness," contagious destruction of housing, and municipal service cuts in New York City: 1. demographics of a housing deficit. Environment and Planning A 21 (12):1585-1602.

Wallace, R. 1991a. Expanding coupled shock fronts of urban decay and criminal behavior: how U.S. cities are becoming "hollowed out." Journal of Quantitative Criminology 7(4):333-356.

Wallace, R. 1991b. Social disintegration and the spread of AIDS: thresholds for propagation along 'sociogeographic' networks. Social Science and Medicine 33(10):1155-1162.

Wallace, R., and K. McCarthy. 2007. The unstable public-health ecology of the New York Metropolitan Region: implications for accelerated national spread of emerging infection. Environment and Planning A 39(5):1181-1192.

Wallace, R., and D. Wallace. 1983. Urban fire as an unstabilized parasite: the 1976-1978 outbreak in Bushwick, Brooklyn. Environment and Planning A 15(2):207-226.

Wallace, R., D. Wallace, J. Ahern, and S. Galea. 2007. A failure of resilience: estimating response of New York City's public health ecosystem to sudden disaster. Health and Place 13(2):545-550.

Wallace, R., D. Wallace, and H. Andrews. 1997. AIDS, tuberculosis, violent crime, and low birthweight in eight US metropolitan areas: public policy, stochastic resonance, and the regional diffusion of inner-city markers. Environment and Planning A 29(3):525-555. 